\title{
Acolhimento no estágio supervisionado: entre modelos e possibilidades para a formação docente
}

\author{
Host in supervised training: \\ between models and possibilities for teacher education \\ Acogimiento em la prática supervisada: \\ entre modelos y posibilidades para la formación docente \\ FLAVIA MEDEIROS SARTI* \\ SIMONE REIS PALERMO MACHAdO DE ARAÚJO**
}

\begin{abstract}
RESUMO
Este artigo focaliza maneiras pelas quais professores em exercício recebem estagiários de prática de ensino em suas classes e como percebem sua atuação na formação dos mesmos. A partir de uma pesquisa pautada em princípios etnográficos, o texto propõe-se a caracterizar duas modalidades de acolhimento no estágio: 1) o acolhimento modelar baseado em uma relação de mestrança entre estagiário e professor supervisor, ancorando-se no primado da visibilidade característico do modelo pedagógico da modernidade (CARVALHO, 2000); e 2) o acolhimento formativo, centrado nos processos de aprendizagem profissional docente vividos pelos estagiários e estruturado sob o primado da invisibilidade, característico da contemporaneidade (BUENO e SOUZA, 2012). As atividades e disposições requeridas dos professores supervisores de estágio nessa segunda modalidade de acolhimento foram percebidas pelos mesmos como sendo significativamente autoformativas e apontam para a emergência de uma lógica de acompanhamento na formação docente.
\end{abstract}

Palavras-chave: Formadores de professores. Acolhimento no estágio. Práticas de acompanhamento. Estágio supervisionado. Formação de professores.

\begin{abstract}
This article focuses on ways in which practicing teachers receive trainees practice teaching in their classes and how they perceive their role in their formation. From a research guided by ethnographic principles, the text proposes to characterize two modality of stage: 1) the model stage based on a relationship between trainee and supervisor teacher, anchoring upon the primacy of the characteristic visibility pedagogical model of modernity (CARVALHO, 2000); and 2) the formation stage, focused on teacher professional learning processes experienced by trainees and structured under the rule of invisibility, characteristic of contemporaneity (BUENO and SOUZA, 2012). Activities and dispositions required of teachers internship supervisors in this second mode of reception were perceived by them as being significantly self-formative and pointed to the emergence of a logical in teacher formation.
\end{abstract}

Keywords: Teacher educators. Host on practical training. Support practices. Supervised internship. Teacher education.

\section{RESUMEN}

Este artículo focaliza maneras por las cuales profesores en ejercicio reciben a practicantes en la práctica de enseñanza en diversas áreas de aprendizaje en sus clases y como notan su actuación en la formación de los mismos. A partir de una pesquisa basada en principios etnográficos, el texto se propone dos modalidades de acogimiento en el periodo en que va a estar practicando: 1) El acogimiento modelar basado en una relación de maestranza entre el profesor practicante y el profesor supervisor, anclándose en la prioridad de la visibilidad característica del modelo pedagógico de la modernidad (CARVALHO, 2000); y 2) El acogimiento formativo, centrado en los procesos de aprendizaje profesional docente vivido por los profesores practicantes estructurado bajo la prioridad de la invisibilidad, característico de la contemporaneidad (BUENO y SOUZA, 2012). Las actividades y disposiciones requeridas de los profesores supervisores de prácticas en esa segunda modalidad de acogimiento fueron percibidas por los mismos como siendo significativamente auto formativas y apuntan para la emergencia de una lógica de acompañamiento de una formación docente.

Palabras clave: Formadores de profesores. Acogimiento en prácticas. Prácticas de acompañamiento. Práctica supervisada. Formación de profesores.

\footnotetext{
* Doutora em Educação pela Universidade de São Paulo (USP); Professora do Departamento de Educação da Universidade Estadual Paulista (UNESP), campus Rio Claro.E-mail: <fmsarti@rc.unesp.br>.

**Mestre em Educação pela Universidade Estadual Paulista (UNESP), campus Rio Claro. E-mail: <simone.palermo76@gmail.com>.
} 
O exame dos trabalhos apresentados nas $15^{\underline{a}}$ e $16^{a}$ edições do Encontro Nacional de Didática e Prática de Ensino (Endipe), ocorridos respectivamente em 2010 e em 2012, sugere que os estágios supervisionados vêm recebendo crescente atenção por parte das pesquisas brasileiras sobre formação docente. Os 118 estudos sobre o assunto divulgados naqueles dois eventos assumem diferentes enfoques, discutindo a importância dos estágios e enfatizando, entre outros aspectos, sua potencialidade no que se refere à articulação entre teoria e prática e ao desenvolvimento de uma postura reflexiva por parte dos futuros professores. No entanto, entre esses trabalhos, somente seis focalizaram a figura do professor da educação básica que recebe o estagiário na escola para a realização do estágio de prática de ensino. Em que pese essa timidez com que se tem discutido o papel do professor da escola no estágio supervisionado, observase no contexto internacional um avanço significativo nas discussões em torno do modelo profissional de formação docente, no qual a figura do "formador de campo" assumida por esses professores - ganha destaque (ALTET, 2009; BORGES, 2008; BUTLEN, 2014).

No âmbito daqueles trabalhos apresentados no Endipe, o professor que recebe estagiários é apresentado como "parceiro" e "corresponsável" pela formação prática dos futuros professores, mesmo sem assumir uma função mais sistemática nessa formação (OLIVEIRA, 2012; FELDKERCHER e PINTO, 2012). Os trabalhos salientam que as atividades de estágio podem ser potencializadas se forem orientadas e supervisionadas de modo partilhado pelos professores da escola e da universidade (RIBEIRO e MOURA, 2012; GALINDO e DOS SANTOS ABIB, 2012). No entanto, Benites, Cyrino e Souza Neto (2013) ressaltam a existência de diversas dificuldades para uma participação mais efetiva dos professores da escola na formação docente, especialmente em função da precariedade de condições nas quais esses professores costumam receber os estagiários. Em grande parte dos casos, eles participam do estágio sem "ter clareza quanto ao papel que podem desempenhar na formação docente, sobre o que se espera da sua participação nessa formação e quais saberes profissionais estão em jogo para o desempenho das tarefas aí previstas" (SARTI et al.; 2015, p. 106).

Esses professores costumam ser deixados a sua própria sorte diante dos estagiários e pouco se sabe sobre o modo como efetivamente elaboram o trabalho que então desempenham. Que reflexões são realizadas pelo professor em exercício durante o período que se relaciona com o estagiário? Que significado ele confere a sua participação na formação docente? Que papel essa participação assume para seu desenvolvimento profissional? Quais são as aprendizagens então construídas? Questões dessa natureza nortearam uma pesquisa que se pautou por princípios etnográficos e teve como referencial empírico o processo de estágio realizado em uma universidade pública paulista. O estágio, naquele contexto investigado, vem sendo compreendido como possibilidade de encontro entre duas gerações profissionais (SARTI, 2009, 2014) compostas, respectivamente, por professores experientes e estudantes do curso de Pedagogia. A proposta do estágio pauta-se na ideia de que os professores em exercício devem partilhar seus saberes, impressões, pensamentos, dúvidas e práticas ligadas à docência cotidiana com os estagiários. Estes, de sua parte, têm a oportunidade de problematizar suas concepções pessoais sobre o ensino ao longo do estágio (SARTI, 2009).

Esse estágio é realizado no quinto semestre do curso e é composto por 105 horas. Cada estudante é recebido por um professor do ensino fundamental I que atua em uma das escolas da rede municipal de ensino. Espera-se que, ao longo dos três meses de estágio, aproximadamente, estagiário e professor estabeleçam uma parceria na elaboração e implementação de atividades com os alunos. A atuação dos professores nessa parceria docente foi objeto de atenção central da pesquisa cujos resultados são aqui apresentados.

\section{OS CAMINHOS DA PESQUISA}

O trabalho orientou-se por uma perspectiva qualitativa e pautou-se em princípios da abordagem etnográfica, que se caracterizam por "estudar o sujeito inserido em seu ambiente natural, por intentar a exploração, a busca sistemática dos dados e a descoberta" (ANDRE, 2005, p. 15-16); e por ter "o pesquisador como o principal instrumento" (SARMENTO, 2003, p. 155) para a coleta e análise dos dados em busca de uma "descrição densa" (GEERTZ,1989) do fenômeno investigado.

Pautando-se por esses princípios, no semestre imediatamente anterior à realização dos estágios, quatro professoras colaboradoras foram entrevistadas, tendo em vista conhecer suas expectativas e motivações para receber os estagiários, suas concepções sobre o estágio, além do papel que atribuíam a si mesmas na relação com o estagiário. O trabalho de observação sistemática durante o processo de estágio foi realizado somente na classe de duas dessas professoras entrevistadas: Agnes, com cinco anos de experiência docente, e Isabel, há mais de 20 anos em exercício no magistério. As duas professoras já tinham experiência em receber estagiários daquela universidade.

As observações ocorreram em todo o período em que se desenvolveu o estágio no ano de 2013. Ao todo, foram dois períodos observados (duas classes), somando 140 horas de observação. Em todos os dias observados foram feitos registros da rotina da sala de aula, 
procurando descrever as interações da estagiária com a professora colaboradora e da estagiária com os alunos. Essas observações eram registradas no diário de campo, sem nenhum tipo de análise ou interpretação prévia, buscando uma descrição literal do que era observado. Imediatamente após o período de observação, já fora da escola, era produzido um relato ampliado, mais narrativo, com informações adicionais sobre os fatos e sobre as impressões da pesquisadora. Como orienta Rockwell (2009), "as notas de campo são passadas a limpo posteriormente e se ampliam para formar o conjunto de registros do trabalho de campo" (p. 59, tradução nossa). Essa é uma fase de anotações mais minuciosas sobre as diversas interações que foram observadas e das conversas informais com as professoras sobre esse período de estágio. Registros que em alguns momentos traziam lacunas devido à dinâmica de uma sala de aula e à impossibilidade de se escutar tudo o que era dito. A partir dessas atividades de campo, foram produzidos outros registros que se constituíram por elementos relativos a situações do cotidiano, que se converteram em material rico para a reflexão e para a "formulação de hipóteses e proposição de novos questionamentos" (TURA, 2003, p. 188).

Enquanto o trabalho de campo era realizado, um terceiro caso despertou especial interesse para a pesquisa, em função do modo bastante ativo pelo qual a professora colaboradora vinha se envolvendo nas atividades de sua estagiária. A professora Fábia possuía à época 15 anos de experiência docente e, naquele ano, recebia uma estagiária em sua sala pela primeira vez. Estava a alguns anos envolvida com outras atividades naquela universidade, especialmente com um grupo de estudos sobre alfabetização. Pensava em ampliar esse seu envolvimento, por meio do ingresso no Programa de Pós-Graduação em Educação, e dizia estar vivenciando um bom momento de sua carreira profissional. Mas, como as atividades do estágio estavam já em fase final, considerou-se pouco viável iniciar um trabalho sistemático de observação na classe daquela professora. A coleta de dados sobre o novo caso limitou-se à realização de uma única entrevista com a professora, à observação de uma reunião entre ela e a estagiária e, ainda, ao exame da comunicação via e-mail estabelecida entre a dupla.

Já com as duas professoras inicialmente selecionadas para o trabalho de campo, foram realizadas duas entrevistas (aquela inicial, antes do começo do estágio, e outra durante o processo de interação com a estagiária). Nesses dois casos, os dados reunidos por meio das entrevistas e das observações estabeleceram uma rica "relação de complementaridade" (ZAGO, 2003, p. 298). A segunda entrevista objetivou, mais especificamente, conhecer os sentidos que as professoras atribuíam às relações construídas com as estagiárias e o teor formativo que imprimiam a tal experiência para seu próprio desenvolvimento profissional.

Conforme os dados eram reunidos, procedeu-se a atividade mais sistemática de análise, focada em seu conteúdo. O trabalho de análise se deu, pois, como um processo interativo com a coleta de dados, conforme sugere Alves-Mazzotti (1998). Considera-se, com Bardin (1977), que todo processo de coleta e "análise de dados é interpretativo, voltado para a compreensão dos fenômenos em seu contexto, em um movimento dialético entre teoria e técnica, hipóteses e interpretações, que vão ramificando, produzindo" (p. 80).

Realizou-se primeiramente uma pré-análise dos dados reunidos por meio das primeiras entrevistas, momento de organização dos materiais a serem analisados, caracterizado por leituras flutuantes mais intuitivas, "muito aberta a todas as ideias, reflexões, hipóteses [...]" (Bardin,1977, p.75). Essas primeiras impressões dos dados foram organizadas em um quadro, que resultou na eleição de algumas categorias empíricas. As segundas entrevistas foram exploradas em conjunto com os registros das observações, de maneira que outras categorias de análise pudessem emergir. A partir dos dados, foram produzidos os primeiros registros analíticos. Essas práticas se inspiram no trabalho etnográfico, conforme proposto por Rockwell (2009): “[...] entre o início e fim, as análises requerem uma série de passos intermediários consistentes na elaboração de escritos sucessivos (notas, registros ampliados, quadros ou fichas, descrições analíticas)" (p. 65, tradução nossa).

Durante essa etapa do trabalho, foram agrupados os dados que respondiam aos objetivos traçados no projeto inicial e que se relacionavam com as categorias empíricas adotadas. Em um trabalho exploratório das informações expostas pelos sujeitos por meio das entrevistas, arquivos foram criados para armazenar os depoimentos das professoras e cenas observadas relacionadas às categorias ressaltadas. A partir dos registros analíticos, produziu-se uma descrição de cada um dos três casos e realizou-se uma exploração dos dados visando a teorizações mais amplas. Essa tarefa demandou a eleição de algumas novas categorias de análise, provenientes da literatura sobre a formação docente, que possibilitassem uma descrição mais densa (GEERTZ, 1989) dos casos focalizados.

Ao se retomarem os registros das observações e as entrevistas concedidas pelas professoras, identificaramse diferentes maneiras pelas quais elas recebiam suas estagiárias. Os papéis que as professoras assumiram ao receberem as estagiárias pareciam guardar relações bastante estreitas com suas concepções sobre a formação docente que, por sua vez, referem-se a certos modelos de formação presentes no campo educacional. Identifica-se, 
então, que as mesmas optaram por acolher as estagiárias e não apenas por recebê-las.

A recepção é considerada aqui como o nível mais inicial e elementar de atuação dos professores colaboradores nos estágios. Trata-se da autorização para entrada e permanência do estagiário em sala de aula para que ele observe de maneira passiva as aulas e práticas dos professores, ou, conforme indicação da instituição de formação inicial, realize regências preparadas sem a participação do professor da classe. Tal modalidade de atuação no estágio reduz-se a permitir ao estagiário o cumprimento da carga horária e das atividades exigidas pela universidade. Já o acolhimento é considerado neste trabalho como uma ação específica que pode ser assumida pelo professor da classe no período do estágio, pressupondo um nível de envolvimento mais elevado que o da mera recepção do estagiário. Trata-se então de oportunizar uma situação diferenciada para observação e regência. Nessa modalidade de colaboração, o professor da classe envolve-se com o estágio, interage com o estagiário e interfere de forma deliberada nos rumos do trabalho. Ele se vê na posição de realizar intervenções formativas junto com o estagiário, interferindo no processo e atuando na formação de um futuro docente.

Assim, a exploração dos dados demandou a eleição de novas categorias - recepção e acolhimento - que possibilitaram caracterizar diferentes modos docentes de atuar junto com os estagiários na escola. As três professoras focalizadas parecem ter optado por acolher suas estagiárias (de acordo com as orientações recebidas pela universidade). Mas, como será discutido a seguir, a natureza desse acolhimento e a compreensão de cada uma delas sobre o estágio e sobre seu próprio papel na formação docente mostraram-se um tanto diversas.

\section{O ACOLHIMENTO MODELAR E A RELAÇÃO DE MESTRANÇA NO ESTÁGIO}

A partir dos depoimentos oferecidos pela professora Isabel, foi possível identificar que, para ela, o estágio revela-se como um período de formação importante que possibilita o contato do estudante com o "real" da docência; uma oportunidade para o "estagiário ver o que acontece no dia a dia". Ela afirmava: "É muito bom! Só não sai do estágio com tudo bem definido na cabeça quem não quer". Para a professora, se o estagiário "ficar apenas com a teoria, vai se assustar quando vier para a sala de aula". Segundo ela, o estudante de licenciatura que "tem essa oportunidade (de vivenciar o estágio)", e experimenta a interação entre uma "estagiária com vontade" de aprender e uma "professora com vontade" de acolher, obtém um ganho para as duas partes. "Não adianta estar pronta para acolher e ela (a estagiária) não ter vontade." Sua expectativa inicial, explica, é sempre receber uma estagiária "comprometida com o trabalho", "com aquilo que realmente quer" e com "vontade de aprender".

A professora salienta que, na proposta de estágio daquela universidade, o papel da educadora que recebe um estagiário inclui "envolvimento" e "responsabilidade" para possibilitar ao futuro docente conhecer uma sala de aula "real/concreta". Ela explica: "Você está formando a professora; tem de ter responsabilidade quando aceita uma estagiária”. Ela ressaltou que o professor em exercício assume a responsabilidade de oferecer ao estagiário a oportunidade de "conhecer o real" e "aplicar, na prática", o que aprende na universidade, sob a forma de teorias. "É uma oportunidade ímpar na vida (do estagiário) para colocar em prática o que aprende". E acrescenta: "Eu ponho a estagiária para ver o que realmente acontece na realidade".

As explicações oferecidas pela professora Isabel sobre seu papel no estágio foram acompanhadas pelo lamento de que, naquele ano, não lhe parecia possível construir relações formativas mais significativas com a estagiária que então recebia em sala, pois considerava que ela não vinha lhe oferecendo "abertura" para tanto. Mostrava-se sem "disposição de aprender", "desinteressada" em desenvolver o trabalho proposto e limitando-se ao cumprimento do estágio como uma mera tarefa. Diante da postura passiva que atribuía à estagiária, a professora passou a assumir, segundo seu depoimento, um papel de "observadora". Este incluía o oferecimento de "dicas", com a expectativa (quase sempre frustrada) de que as mesmas fossem "colocadas em prática" nas aulas regidas pela estagiária. Seguia descontente com o desempenho dela, a quem costumava comparar a outras estudantes (mais dispostas a aprender) que havia recebido nos anos anteriores.

Apesar de suas queixas com relação à estagiária, durante o período de estágio, a professora costumava disponibilizar parte de seu tempo para estar com ela e ouvi-la sobre o que planejava para as aulas seguintes. Esse era o principal momento em que Isabel oferecia-lhe "dicas" de como o trabalho deveria ser desenvolvido e sobre modo como os materiais deveriam ser organizados antecipadamente. Ofereceu-lhe, inclusive, alguns materiais elaborados em anos anteriores, entre os quais o projeto realizado por outra estagiária, com a mesma temática (escolhida nos dois casos por ela). Tais "dicas" eram oferecidas com a expectativa de que fossem implementadas pela estagiária, de modo que o trabalho realizado se aproximasse mais claramente do que era esperado por Isabel. A professora parecia ansiar que as estagiárias que recebia aprendessem em sua classe o que ela considerava como sendo boas práticas (modos de 
se relacionar com os alunos, de organizar o tempo e o espaço da aula, de apresentar os conteúdos, etc.), que lhes possibilitassem um bom desempenho docente na "escola real".

Durante as observações, foi possível presenciar o questionamento da professora em relação ao plano de aula realizado pela estagiária, bem como à organização dos materiais necessários para desenvolver a aula e à elaboração do registro que era colocado na lousa, ao final do trabalho, para que os alunos copiassem. $\mathrm{O}$ registro de um dos momentos de orientação exemplifica as questões que permeavam a maioria das conversas que ocorria às quartas-feiras, dias em que a estagiária ia à escola para apresentar à professora seu plano de aula para ser desenvolvido na sexta-feira.

\begin{abstract}
Você sempre tem que ter na mão, antes de qualquer coisa, a primeira coisa, munida do seu material. Tudo na cabeça. Mas tem que ter o plano B. No caminho, as coisas podem mudar. Ao mesmo tempo em que eles demoram, eles podem ser rápidos. Tem sempre que ter duas atividades. Isso não é só pra agora, na regência. Se for seguir no magistério, ter sua classe. Por isso na nossa rotina a gente sempre prepara mais do que vai dar. E também não gera conversas. Se parar para pensar "e agora, o que eu vou fazer?", a classe já se agitou. Você não pode deixar perder o fogo. Por exemplo: "Olha como ele desenhou! Olha, este! Agora vamos para outra". Sempre dando continuidade à aula. (Prof. Isabel, maio, 2013)
\end{abstract}

Como enfatizado várias vezes por Isabel, a "escola real", vivenciada no estágio, revela-se como lugar de aprendizagens de boas práticas docentes; práticas essas que assumem uma dimensão modelar. A relação que estabelecia com a estagiária durante o estágio e as expectativas que nutria a respeito de seu desempenho apontam para uma concepção de ensino como arte, estruturada sob o "primado da visibilidade" e associada aos princípios de observação e imitação das boas práticas pedagógicas (CARVALHO, 2000). Embora a professora enfatizasse a importância da formação acadêmica, por meio da qual a estagiária poderia entrar em contato com teorias a serem "aplicadas" na prática.

O papel do estagiário, nesse modelo formativo, é o de se deixar guiar, mostrando vontade de aprender e valorizando os ensinamentos oferecidos pela professora. Espera-se que, por meio da observação e de um longo período de contato com o professor, o estagiário possa desvendar os "segredos" da docência, apropriando-se dos macetes ligados ao ensino. A aprendizagem da arte de ensinar corresponde, sob essa perspectiva, à "cópia de modelos" (CARVALHO, 2000) que, no entanto, não se limita à mera reprodução de procedimentos exemplares. Esta requer do aprendiz a capacidade de extrair analiticamente, por meio da observação, os princípios que regem as práticas docentes do "mestrede-ensino"1 (SARTI, 2000) e "aplicá-los inventivamente" (CARVALHO, 2000, p. 113).

A professora Isabel declarou ao final de um dos dias de estágio que esperava "melhora" na postura da estagiária, na expectativa de que sua intervenção "surtisse efeito". "Eu falei com ela, agora vamos ver." A aprendizagem do ofício docente nesses termos exige disciplina, organização e repetição inventiva de procedimentos exemplares. Mas, de todo modo, trata-se de uma formação fundamentada na reprodução, que se utiliza de "estratégias que valorizam a demonstração e a imitação" (ALARCÃO, 2001, p. 23). $\mathrm{O}$ mestre figura como "aquele que transmite o que sabe fazer" (ALARCÃO, 2001, p. 23), demonstrando ao aprendiz suas técnicas de trabalho, que por ele devem ser apropriadas. Nesses termos, o estagiário é visto como o "aprendiz que aprende o saber acumulado" (PIMENTA e LIMA, 2010, p. 36) na cultura docente.

Essa modalidade de recepção do estagiário foi denominada no âmbito da pesquisa aqui apresentada como acolhimento modelar, realizada sob uma relação de mestrança. Na literatura francesa, a mesma ideia aparece ligada ao termo compagnonnage, "modalidade de aprendizagem de um ofício, em que o aprendiz realiza um longo estágio no ateliê ou oficina de um mestre" (BUTLEN, 2014, p. 6). A mestrança, enquanto relação formativa, teve origem nas escolas de ofício medievais. Pouco antes do século XI, as oficinas dos mosteiros eram o lugar em que se formavam os artesãos de vários gêneros, espécie de treinamento dos jovens em "laboratórios artesanais para instruir a mão-de-obra necessária" (RUGIU,1998, p. 26). As práticas de ensino eram pautadas na tradição, na visibilidade e na reprodução de práticas exemplares. Segundo Rugiu (1998), o aprendiz passava a acompanhar sistematicamente o trabalho de um "mestre-adjunto", buscando "deduzir" alguns segredos do ofício, a ponto de exceder em sua prática os ensinamentos oferecidos. $\mathrm{O}$ trabalho artesanal se coloca como tradição pelo princípio da transmissão do saber do ofício às novas gerações, de modo que "os aprendizes, em essência, aprendiam fazendo" (RUGIU, 1998, p. 19).

Embora esse modelo formativo ancorado na aprendizagem imitativa do ofício tenha origens medievais, é na modernidade pedagógica que passa a figurar na formação docente, com o advento das Escolas Normais, onde "o formador é, simultaneamente, um

\footnotetext{
" A expressão "mestres-de-ensino" foi proposta por SARTI (2000) ao referir-se aos professores que atuavam nos cursos de formação inicial docente oferecidos em nível médio (na Habilitação Específica para o Magistério e no Centro Específico de Formação e Aperfeiçoamento do Magistério).
} 
professor experiente e um modelo" (ALTET, 2000). Mas a contemporaneidade pedagógica tem trazido novas lógicas para o campo da formação docente que podem ser percebidas nas práticas e relações estabelecidas por professores que colaboram com o estágio supervisionado, como parece ser o caso das outras duas professoras focalizadas na pesquisa.

\section{O ACOLHIMENTO FORMATIVO COMO RECURSO DE SOCIALIZAÇÃO PROFISSIONAL DOCENTE}

Assim como a professora Isabel, a professora Agnes considerava o estágio como importante recurso para que o futuro professor entrasse em "contato com a sala de aula de verdade", estabelecendo relações com as teorias estudadas na universidade e experimentando os fazeres docentes no cotidiano da escola. Seguindo a perspectiva de estágio proposta pela universidade, a professora enfatizava a necessidade de o estagiário participar, ao lado da professora da classe, das diversas tarefas que compõem o dia a dia da docência. Agnes, assim, como Isabel, optou por acolher sua estagiária durante o período do estágio, interagindo com ela e oportunizando situações para seu envolvimento com os alunos e com as tarefas docentes.

Agnes ressaltava que o acolhimento de estagiários sob essa perspectiva implicava uma sobrecarga de trabalho para os professores da escola e mais uma responsabilidade a ser assumida, para a qual nem sempre os professores se sentiam preparados. Sobre suas dúvidas acerca do acolhimento de estagiários, ela explicou: "No começo, eu não sabia bem o que fazer. Eu não sabia qual era minha parte. Na verdade, ainda nem sei muito bem qual é minha parte (1 a entrevista, dezembro, 2012). Ela se dizia disposta a "assessorar" o estagiário, oferecendo-lhe "espaço de troca", mostrando-lhe os instrumentos do trabalho docente e deixando que "ele fizesse a parte dele". Por sua vez, Agnes também parecia disposta a experimentar novos modos de fazer e de pensar na situação de ensino. Explicou que a presença do estagiário tende a mudar o trabalho previamente planejado para o período, posto que, não raramente, o professor se vê diante da decisão de aceitar uma proposta ou sugestão feita por ele.

Os dados reunidos por meio das observações em sua classe sugerem que o acolhimento da estagiária por parte de Agnes assumia, em muitos momentos, dimensões claramente formativas. Em várias ocasiões de "prática acompanhada" (SARTI, 2013), em que as aulas eram regidas pela estagiária na presença da professora, Agnes tentava deixá-la à vontade para desenvolver o projeto planejado em conjunto pelas duas. Diversas atividades do cotidiano da turma puderam ser vivenciadas pela estagiária, que costumava auxiliar os alunos ou a própria docente, participando de momentos de correções de cadernos e de sondagens dos níveis de escrita, por exemplo. No decorrer das aulas, costumavam conversar também sobre o desenvolvimento dos alunos e sobre as atividades.

Em algumas ocasiões em que a estagiária desenvolvia o trabalho com os jogos (essa era a estratégia proposta pelo projeto das duas com foco em alfabetização), a professora intervinha na aula quando considerava necessário. Entretanto, cabe ressaltar, sobre esse tipo de intervenção da professora na atuação da estagiária, que muitas vezes sua atenção estava mais voltada para o processo de aprendizagem dos alunos. Sempre que percebia que alguma explicação oferecida pela estagiária não havia ficado clara, ou que um aluno estava com dúvida em certo traçado de letra, levantava-se e, após pedir licença à estagiária, (re)assumia o controle da situação de ensino. Somente após esclarecer as dúvidas dos alunos, cedia novamente a palavra para a estagiária. Agnes contou em entrevista que esse tipo de intervenção não lhe deixava muito confortável. E que esta ocorria porque priorizava a aprendizagem de seus alunos, em detrimento (como ela mesma percebia) do processo de aprendizagem da estagiária. Como ela mesma ressaltou, não lhe parecia claro o seu papel em relação à estagiária e o tipo de intervenção que deveria fazer. Assim, diante dessa indefinição quanto a seu papel na formação da estagiária, Agnes optava por garantir os momentos de aprendizagem de seus alunos.

Após cinco anos recebendo estagiários, a professora elaborou estratégias para as primeiras interações. Explicou que uma de suas primeiras ações é mostrar ao estagiário os documentos que utiliza para organizar seu trabalho. Apresenta o Projeto Político Pedagógico da escola e seu plano de ensino, e mostra como elabora um plano de aula e seu diário de classe. Agnes mostrava-se empenhada em familiarizar o estagiário com o ambiente e com o trabalho docente. Parecia querer delimitar, diante dele, o lugar docente na escola.

Durante as aulas observadas, a aproximação do estagiário com o lugar docente revelou-se, de fato, como uma preocupação para Agnes. Logo no primeiro dia de estágio, colocou uma mesa grande ao lado da sua para que a estagiária pudesse se acomodar. E, ao ser questionada sobre essa prática, explicou: "Não vou colocar o estagiário lá atrás. Ele não está na condição de meu aluno. Ele está de parceiro comigo. Então, o lugar dele é ali na frente, junto comigo, pra ver, participar, trocar ideia". Essa estratégia de acolhimento está fundamentada em uma ideia que possibilita ao estagiário olhar para a situação de sala de aula a partir da perspectiva docente. Com esse tipo 
de atitude, Agnes mostrava-se interessada na socialização profissional da estagiária e em sua iniciação no trabalho e na cultura docente.

Agnes reservou um tempo de sua jornada para dialogar com a estagiária durante o horário de trabalho pedagógico individual (HTPI). Como canal de comunicação, a professora disponibilizou também o próprio e-mail e o telefone pessoal. Por essas vias, as duas discutiam o projeto de trabalho e as atividades propostas pela estagiária, e conversavam sobre os níveis de aprendizagem dos alunos e sobre outras questões relativas aos processos de ensino e à vida da escola. "Eu preciso sentar com esse estagiário, independentemente de estar em sala de aula ou não. Tem que sentar uma hora com ele. HTPI é um horário bom que tem que conversar. Tem que trocar ideia com ele. Ver o que ele está precisando saber. O que ele está fazendo, pra onde ele quer ir" (Prof ${ }^{\mathrm{a}}$ Agnes, $1^{\mathrm{a}}$ entrevista, dezembro, 2012). "[...] eu tenho de agregar alguma coisa na vida dele, além do que ele vai observar. Tem que formalizar alguma coisa na cabeça dele. Pelo menos pra ele ter alguma coisa pra pensar sobre estágio [...]" (Agnes, junho, 2013).

Ao longo do processo de interação com a estagiária, Agnes pareceu desenvolver um trabalho de acolhimento que visava a oferecer à estagiária oportunidades de ocupar, mesmo que temporariamente, o lugar docente e, desse modo, poder perceber a docência a partir de uma perspectiva específica, ligada ao trabalho e à cultura docente. Não se tratava, para ela, de oferecer modelos de atuação docente, e sim de estimular o processo de socialização profissional da estagiária, integrando-a às atividades e modos de fazer docentes.

Semelhante perspectiva foi identificada no modo como a professora Fábia acolheu sua estagiária e com ela desenvolveu o trabalho naquele semestre. Apesar de se contar com uma quantidade consideravelmente menor de dados acerca desse terceiro caso, foi possível identificar nele indícios de que o acolhimento realizado pela professora assumiu contornos formativos. Como antes mencionado, sobre esse caso, dispõe-se apenas dos dados reunidos por meio de uma entrevista concedida pela professora Fábia (na fase final do estágio), da observação de uma reunião que ela realizou com a estagiária e das mensagens de e-mail que trocaram no período. Esses dados revelam a existência de uma interação bastante intensa entre professora e estagiária, que se configurava em uma parceria nas atividades docentes (demanda da universidade envolvida). Professora e estagiária costumavam dialogar bastante sobre o trabalho que vinham desenvolvendo na classe e elaboravam conjuntamente as aulas. A comunicação entre as duas ultrapassava os muros da escola, e era estabelecida por meio de recursos variados (redes sociais, e-mail, telefone).
Sobre o conteúdo das interações estabelecidas, chamou especial atenção o fato de a professora parecer bastante empenhada em tornar mais claros para a estagiária os princípios que embasam seu trabalho didático, realizado a partir da perspectiva da pedagogia por projetos. Fábia costumava expor os pressupostos que percebia em cada atividade que elaboravam conjuntamente e elencar questões sobre os objetivos e procedimentos previstos no trabalho que propunham. Partilhava com a estagiária seu processo de elaboração e de reflexão sobre as intervenções a serem realizadas junto com os alunos A professora procurava, assim, envolvê-la na tarefa de explicitar e, de certo modo, teorizar as práticas que vinham desenvolvendo juntas. A mensagem a seguir exemplifica o processo:

[...] Pensei em solicitar aos alunos o registro de tudo o que foi dito por meio de uma ilustração, e em seguida o registro escrito dessa mesma ilustração... O que (você) acha? Porque esta turma, como comentei com você, é muito imatura, então gostaria de "fechar" cada aula. Preocupo-me com a disciplina nas atividades para melhor orientá-los [...]. (Trecho de um dos e-mails escrito pela professora,junho, 2013)

$\mathrm{Na}$ rotina da sala de aula, segundo depoimento da professora, seguia a parceria com a estagiária: enquanto uma delas interagia diretamente com o grupo inteiro, a outra fazia anotações das colocações dos alunos e das intervenções. Quando as crianças passavam a realizar atividades individuais, em duplas ou grupos, as duas realizavam intervenções no atendimento às crianças. Nos dias em que a estagiária estava na escola, os HTPIs da professora eram, segundo seu depoimento, destinados à discussão sobre o trabalho que vinham realizando. Fábia parecia ter clareza sobre a dimensão formativa de sua interação com a estagiária:

[...] o comprometimento com o trabalho que eu assumi durante o período de estágio). Eu tive que, assim, eu não tinha que falar só pra mim, eu tinha que falar pra ela também. Era uma energia que eu tinha que pôr, por exemplo: eu perdi todos os meus HTPIs. (Fábia, entrevista, junho, 2013)

Fábia enfatizava que, ao dispor de seus HTPIs para o atendimento da estagiária, havia fortalecido a relação de apoio mútuo que vinham estabelecendo. Mas, apesar do clima de companheirismo estabelecido na dupla, ela parecia compreender a diferença geracional que se impunha na relação. Cada uma delas vivia uma fase específica da vida profissional. Fábia parecia reconhecer sua parceira como uma iniciante e identificar seu lugar (de formadora) na relação. Assim como Agnes, procurava iniciá-la em uma perspectiva docente: 
Aí eu sempre dizia pra ela (não sei se foi no começo ou depois), "Observa certas coisas; não deixa passar certas coisas. Olha aquela criança. Olha como ela interage. Olha como ela não interage. E olha como a gente tem que olhar pra ela ou não". (Fábia, entrevista, junho, 2013)

A professora ressaltava que as aprendizagens no estágio não são "automáticas", fazendo-se necessária a intervenção sistemática do professor experiente. Nesse sentido, durante a reunião observada, a estagiária comentou: "Depois, os alunos queriam trabalhar profissões. Eu queria esse! Estava tudo na (minha) cabeça". Prontamente, Fábia interveio, assinalando pressupostos presentes na proposta de trabalho em curso (baseada na Pedagogia por projetos): "Esse projeto é muito dinâmico, não tem nada pronto!”.

Para a professora Fábia, ocupar o papel de formadora naquela relação implicava envolver-se com seu próprio processo de aprendizagem profissional. A reflexão sobre sua própria prática e suas convicções era um exercício constante, impulsionado pela experiência de acolher uma estudante em fase inicial da formação docente: "Eu acho que foi válido pra mim, porque, toda vez que eu falava alguma coisa com a estagiária, eu tentava ver se eu fazia mesmo. Eu fiz esse exercício todo o tempo: será que eu faço de verdade?" (Profa Fábia, entrevista, junho, 2013). Acolher um estagiário parecia significar, para Fábia, voltar-se para si mesma enquanto professora. Possibilitava-lhe refletir. "No sentido, assim, eu... eu estou dizendo pra ela o que deve ser feito, baseado numa teoria tal, mas eu faço realmente isso?" (entrevista, junho, 2013).

\section{CONSIDERAÇÕES FINAIS: EM DIREÇÃO À LÓGICA DO ACOMPANHAMENTO NO ESTÁGIO}

Os casos acima expostos, das professoras Agnes e Fábia, apresentam similaridades no que se refere às concepções relativas ao estágio, considerado como parte do processo de socialização profissional docente, bem como à modalidade de acolhimento da estagiária, de contornos claramente formativos.

As duas professoras realizaram um tipo de acolhimento que se denomina aqui como sendo formativo, no qual o professor está mais atento ao processo de aprendizagem profissional docente do estagiário. Sob essa modalidade de acolhimento, as professoras focalizadas pela pesquisa assumiam uma intervenção mais efetiva na formação de suas estagiárias. Tinham em vista instigar e subsidiar sua socialização em modos de agir docente e de considerar as situações de ensino. Pareciam empenhadas em possibilitar que as estagiárias "experimentassem o lugar docente", para que percebessem o ensino, os alunos e os demais aspectos da vida escolar sob uma perspectiva ligada ao magistério. As duas professoras demonstravam reconhecer que sua função no estágio seria o de partilhar com as estagiárias essa perspectiva específica.

As relações então estabelecidas com as estagiárias pareciam ter assumido "efeitos ascendentes" (SARTI, 2009 , p. 137) na formação daquelas duas professoras, implicando mudanças em seus modos de agir e levando-as a problematizar seus gestos e decisões cotidianos. Especialmente no caso da professora Fábia, esse processo parece ter suscitado atitudes reflexivas, revelando um claro potencial autoformativo.

O potencial (auto)formativo dessa modalidade de acolhimento o alinha ao modelo pedagógico mais contemporâneo, no qual os sujeitos são instados a buscar referências em si mesmos, por meio da reflexão, do voltar-se para suas próprias práticas (BUENO, SOUZA, 2012). Tal modelo, em oposição ao modelo pedagógico moderno (CARVALHO, 2000), assume a invisibilidade como primado (BUENO, SOUZA, 2012). Diferentemente do modelo anterior, as referências para a ação do sujeito não são externas, mas emergem da reflexão e da problematização de suas próprias práticas. Espera-se que, nesses processos, os sujeitos sejam capazes de se "(re)modelarem" (BUENO, SOUZA, 2012) continuamente.

Tal modelo pedagógico contemporâneo afina-se a uma perspectiva transicional (ROQUET, 2009), na qual a formação é integrada à vida adulta e ao seu dinamismo. A formação, sob essa ótica, dá-se em movimento, pressupondo que "o caminho se faz ao caminhar". No estágio, professor e estagiário assumem uma relação de "companheirismo" com contornos específicos.

Um acompanhamento formativo cujo foco está no futuro da existência do acompanhado que, neste caso, é o estagiário. Em tal relação, aquele que acompanha (a professora parceira) coloca à disposição do acompanhado condições necessárias para que ele possa descobrir suas possibilidades, organizando situações propícias para a formação ou aproveitando as situações favoráveis (SARTI, 2013, p. 94).

O acompanhamento figura então como uma modalidade de recepção nos estágios em que o professor desenvolve práticas bastante intencionais e sistemáticas como formador de campo. Tal modalidade de intervenção requer um grau avançado de engajamento por parte dos professores colaboradores para favorecer, segundo Vial e Caparros-Mencacci (2007), o desenvolvimento

2 "Caminhante, não há caminho, o caminho se faz ao caminhar" Antonio Machado, poeta espanhol. 
do acompanhado, colocando-se a seu serviço; não atuando nem como guia, que indica os melhores caminhos, nem como mestre, que julga os caminhos escolhidos. Nesse tipo de relação formativa, o formador se responsabiliza pela elaboração e implementação de dispositivos específicos que possibilitem a atividade de acompanhamento do sujeito em formação. Essas demandas contrastam com as precárias condições sob as quais as professoras aqui focalizadas desenvolvem o acolhimento das estagiárias. Para elas, o envolvimento no estágio representava uma sobrecarga de trabalho, não reconhecida e amparada institucionalmente (em forma de remuneração, possibilidades de progressão na carreira e, sobretudo, formação específica para a intervenção na formação profissional).

No entanto, é possível afirmar que do trabalho desenvolvido por elas naquele período emergem aspectos afinados com a lógica do acompanhamento acima descrita. As professoras mostraram-se interessadas no processo de socialização profissional das estagiárias, estabelecendo um canal de comunicação com elas e disponibilizando parte de seu tempo de trabalho para atendê-las (conhecer suas expectativas e propostas de trabalho e orientá-las). Sobretudo, apoiavam e buscavam favorecer o processo de descoberta da docência por parte das estagiárias, oferecendo-lhes, a cada momento, recursos para a continuação do processo de aprendizagem profissional em que estavam envolvidas. $\mathrm{O}$ acolhimento formativo que realizavam no estágio avançava em direção à perspectiva do acompanhamento, mesmo que elas não assumissem mais efetivamente o lugar institucionalmente definido de formadoras e as práticas sistemáticas aí previstas.

A atuação daquelas professoras junto com as estagiárias, mesmo realizada sob condições tão frágeis, oferece pistas sobre o importante lugar a ser ocupado pelos professores da educação básica na formação das novas gerações docentes, como representantes de todo o grupo profissional docente (SARTI, 2013). Uma formação docente dessa ordem, como uma forte dimensão socioprofissional (SOREL, 2005), poderá "ultrapassar a perspectiva escolarizada que comumente orienta as incursões dos futuros professores na vida da escola, para lhes possibilitar conhecê-la como um espaço de docência" (SARTI, 2013, p. 96). O caminho está sendo trilhado.

\section{REFERÊNCIAS}

ALARCÃO, I. 'Do olhar supervisor ao olhar sobre a supervisão' In: RANGEL, Mary (org.). Supervisão pedagógica: princípios e práticas. 2. ed. Campinas: Papirus, 2001. p. 11-56.

ALTET, M. Análise das práticas dos professores e das situações pedagógicas. Porto: Porto Editora, 2000.
ALTET, M. Des tensions entre professionnalisation et universitarisation en formation d'enseignants à leurs articulation: curriculum et transations nécessaires. In: ETIENNE et al. (org.). L'université peut-elle vraiment former les enseignants? Bruxelas: De Boeck, 2009.

ALVES-MAZZOTTI, A.; GEWANDSZNADJDER, F. o método nas ciências naturais e sociais: pesquisa quantitativa e qualitativa. São Paulo: Pioneira, 1998. 203 p.

ANDRÉ, M. E. D. A. de. Etnografia da prática escolar. 12. ed. Campinas (SP): Papirus, 2005.

BARDIN, L. Análise de conteúdo. Lisboa: Edições 70, 1977.

BENITES, L. C. O professor-colaborador no estágio curricular supervisionado em Educação Física: perfil, papel e potencialidades. 2012. $180 \mathrm{fl}$. Tese (Doutorado) - Unesp, Rio Claro.

BENITES, L.; CYRINO, M.; SOUZA NETO, S. Estágio curricular supervisionado: a formação do professor-colaborador. Olh@res, Guarulhos, v. 1, n. 1, p. 116-140, maio 2013.

BORGES, C. A formação docente em Educação Física em Quebec: saberes espaços, culturas e agentes. In: XIV ENDIPE, Trajetória e processos de ensinar e aprender: práticas e didáticas. Porto Alegre: EDIPUCRS. 2008. Vol. 2, p. 147-174.

BUENO, B.; SOUZA, D. Pedagogia contemporânea e formação de professores em serviço: lógicas e dispositivos de um modelo em expansão. In: BITTAR, M. Formação de professores. São Paulo: Edufscar, 2012.

BUTLEN, M. O desafio da participação dos profissionais da escola na formação dos professores: uma análise sobre a experiência francesa de universitarização e profissionalização docente, 2014 (texto ainda não publicado).

CARVALHO, M. M. C. de. Modernidade pedagógica e modelos de formação docente. São Paulo em Perspectiva, São Paulo, v. 14, n. 1, jan./mar. 2000.

CYRINO, M. Formação inicial de professores: o compromisso do professor-colaborador e da instituição escolar no processo de estágio supervisionado. 2012, 233 f. Dissertação (Mestrado) Unesp, Rio Claro.

ENCONTRO NACIONAL DE DIDÁTICA E PRÁTICA DE ENSINO. XV ENDIPE (15., 2010, Belo Horizonte, MG). Convergências e tensões no campo da formação e do trabalho docente: políticas e práticas educacionais [recurso eletrônico]/15. ENDIPE. Belo Horizonte, 2010. [CD-ROM].

Encontro Nacional de Didática e Prática de Ensino. XVI ENDIPE (16., 2012, Campinas, SP). Didática e práticas de ensino: compromisso coma escola pública, laica, gratuita e de qualidade [recurso eletrônico]/16. ENDIPE Campinas: UNICAMP, 2012. [CD-ROM.].

GALINDO, M.; DOS SANTOS ABIB, M. ESCOLA, Universidade e estágio supervisionado: sentidos atribuídos pelos professores das escolas básicas. XVI ENDIPE (16., 2012, Campinas, SP). Didática e práticas de ensino: Compromisso coma escola pública, Laica, gratuita e de qualidade [recurso eletrônico]/16. ENDIPE. Campinas: UNICAMP, 2012. [CD-ROM].

GEERTZ, C. A interpretação das culturas. Rio de Janeiro: Guanabara, 1989. 
DE OLIVEIRA, R. M. M. A. Formação de professores na modalidade a distância: indicações a partir de uma experiência de estágio supervisionado. In: XVI ENDIPE (16., 2012, Campinas, SP). Didática e práticas de ensino: compromisso com a escola pública, laica, gratuita e de qualidade [recurso eletrônico]/16. ENDIPE. Campinas: UNICAMP, 2012. [CD-ROM.].

FELDKERCHER, N.; C. S. M. G. M. O estágio na formação de professores: perspectivas dos estagiários dos cursos de matemática presencial e a distância. In: XVI ENDIPE (16., 2012, Campinas, SP). Didática e práticas de ensino: compromisso com a escola pública, laica, gratuita e de qualidade [recurso eletrônico]/16. ENDIPE. Campinas: UNICAMP, 2012. [CD-ROM].

NÓVOA, A. Para uma formação de professores construída dentro da profissão. Professores: imagens do futuro presente. 1. ed. Educa: Lisboa, 2009, cap.295

PIMENTA, S.; LIMA, M. Estágio e docência. Cortez: São Paulo, 2010.

RIBEIRO, F.; MOURA, M. A reflexão no processo formativo em prática de ensino e no estágio: contribuições da teoria da atividade. In: III Congresso Internacional sobre Prodesorado Principiante e Inserción Profesional a la Docencia. 2012.

ROCKWELL, E. La experiencia etnográfica: historia y cultura en los procesos educativos. Buenos Aires: Paidós, 2009.

ROQUET, P. L'emergence de l'accompagnement. Une nouvelle dimension de la formation. Recherche et Formation, n. 62, p. 13-24, 2009.

RUGIU, A. S. Nostalgia do mestre artesão. Caminas: Autores Associados, 1998.

SARMENTO, M. J. O estudo de caso etnográfico em educação in ZAGO, N. et al. (orgs.). Itinerários de pesquisa: perspectivas qualitativas em sociologia da educação. Rio de Janeiro, OP\&A Editora, 2003. p. 137-117.

SARTI, F. M. Mestres-de-ensino: um estudo etnográfico sobre a dimensão ética do ofício de formar professores. 2000. 190f. Dissertação (Mestrado em Educação) - Faculdade de Educação, Universidade de São Paulo, São Paulo, 2000.
SARTI, F. M. Parceria intergeracional e formação docente. Educação em Revista, Belo Horizonte, v. 25, n. 2, p. 133-152, 2009. http://dx.doi.org/10.1590/S0102-46982009000200006

SARTI, F. M. Pelos caminhos da universitarização: reflexões a partir da masterização dos IUFM franceses. Educação em Revista, Belo Horizonte, v. 29, n. 4, p. 215-244, 2013. http:// dx.doi.org/10.1590/S0102-46982013000400010

SARTI, F. M. Relações intergeracionais e alternância na formação docente: considerações a partir de uma proposta de estágio supervisionado. Cadernos de Educação UFPel, Pelotas, v. 46, p. 83-99, 2014.

SARTI, F. M. et al. De mestres de ensino a formadores de campo no estágio supervisionado. Cadernos de Pesquisa, v. 45, n. 155 , p. 100-117, 2015. http://dx.doi.org/10.1590/198053142928

SOREL, M. Préambule. In: SOREL, M.; WITTORSKI, R. (orgs.). La professionnalisation en actes et en questions. Paris: L'Harmattan, 2005. p.7-10.

SOUZA NETO, BENITES. L. Os desafios da prática na formação inicial docente: experiência da Educação Física da UNESP de Rio Claro. Cadernos de Educação, Pelotas, p. 02-22, set./dez. 2013.

TARDIF, M. Saberes profissionais dos professores e conhecimentos universitários. Disponível em: <eleduc.unisa.br/ teleduc/cursos/diretorio/apoio_5427 368/TARDIF_Saberes profissionais dos professores.pdf>. Acesso em: 02 jul. 2014.

TURA, M. L. R. A observação do cotidiano escolar. In: ZAGO, N.; CARVALHO, M. P.; VILELA, R.A. T. (org.). Itinerários de pesquisa: perspectivas qualitativas em Sociologia da Educação. Rio de Janeiro: DP\&A, 2003, p. 183-206.

VIAL, M.; CAPARROS-MENCACCI, N. L'accompagnement professionnnel? Méthode à l'usage des praticiens exerçant une fonction educative. Bruxelas: De Boeck, 2007.

ZAGO, N. (org.). Itinerários de pesquisa: perspectivas qualitativas em Sociologia da Educação. Rio de Janeiro: DP\&A, 2003

Submetido em: 17/11/2014

Aprovado em: 24/11/2015 